\title{
Spectral Investigations of Fullerene-Porphyrin Complexes
}

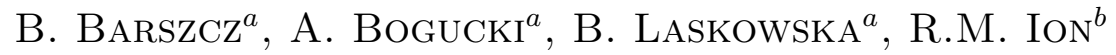 \\ AND A. GRAJA ${ }^{a, *}$ \\ ${ }^{a}$ Institute of Molecular Physics, Polish Academy of Sciences \\ Smoluchowskiego 17, 60-179 Poznań, Poland \\ ${ }^{b}$ VALAHIA University of Targoviste, 130082 Targoviste, Romania
}

Dedicated to the memory of Professor Jerzy Prochorow

\begin{abstract}
Spectral investigations of some $\mu$-oxo-dimer complexes of trivalent metals $(\mathrm{Mn}, \mathrm{Fe})$ with two different ligands: tetraphenylporphyrin and tetranaphthylporphyrin (TNP), and fullerene $\left(\mathrm{C}_{60}\right.$ and $\left.\mathrm{C}_{70}\right)$ complexes with $\mu$-oxobis $\left[5,10,15,20\right.$-tetraarylporphyrinatometal (III)] (TXP-M) ${ }_{2} \mathrm{O}$ dimer, where $\mathrm{M}=\mathrm{Fe}, \mathrm{Mn}$ and $\mathrm{X}=$ phenyl or naphthyl, are presented. Discussion of the main electronic and vibrational bands observed in the UV-Vis-IR and Raman spectra of both classes of fullerene-porphyrin systems is given. Experimental data are completed with the quantum chemical calculations of $\mathrm{MnTNP}^{+}$component.

PACS numbers: 33.20.-t, 33.20.Ea, 33.20.Fb, 33.20.Kf, 33.20.Tp, 36.40.-c, 31.15.Ar, 33.15.Bh
\end{abstract}

\section{Introduction}

Recently, many studies have been focused on synthetic donor and acceptor arrays with well-defined architectures to develop artificial photosynthetic systems, new catalysts, and other systems applicable in molecular electronics and nanotechnology.

The unique shape of the fullerenes $\mathrm{C}_{60}$ and $\mathrm{C}_{70}$ combined with their distinct physical properties make them good candidates for preparation of large, supramolecular aggregates [1-4]. On the other hand, porphyrins with their electronic absorption properties have been widely used as electron-donating species in photoactive molecular dyads [5-8]. The porphyrins and fullerenes molecules are spontaneously attracted in solution to each other. Such supramolecular aggregates can be exploited to produce ordered arrays of interleaved porphyrins and fullerenes. This arrangement identifies the fullerene-porphyrin interaction as a structure-

*corresponding author 
-defined element. Due to the presence of a metal into the inner porphyrin ring and oxygen binding the two porphyrinic macrocycles or porphyrin $\mu$-oxo-dimers play an essential role in various catalytic processes [9]. For an enhanced understanding of the chromophore interaction between fullerenes and various porphyrin-derived dyes we have performed spectral studies of selected porphyrin $\mu$-oxo-dimers and their complexes with fullerenes, using both experimental and theoretical methods. These experimental data supplemented with ab initio calculations should be important instructions for design and preparation of the solar energy converters.

\section{Experimental}

The $\mu$-oxo-dimer complexes of trivalent metals (Mn, Fe) with two different ligands: tetraphenylporphyrin (TPP) and tetranaphthylporphyrin (TNP) have similar structures; for one of them the structure is shown in Fig. 1. Above

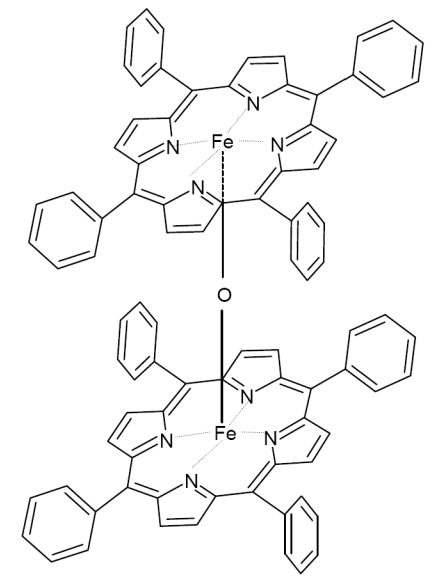

Fig. 1. Structure of the $\mu$-oxo-dimer of trivalent iron (Fe) with TPP ligand.

mentioned $\mu$-oxo-dimers as well as the fullerene $\left(\mathrm{C}_{60}\right.$ and $\left.\mathrm{C}_{70}\right)$ complexes with $\mu$-oxobis [5,10,15,20-tetraarylporphyrinatoiron (III)] (TXP-Fe) ${ }_{2} \mathrm{O}$ dimer, where $\mathrm{X}$ $=$ phenyl or naphthyl, and $\mu$-oxobis[5,10,15,20-tetraarylporphyrinatomanganese (III)] (TXP-Mn $)_{2} \mathrm{O}$ dimer, where aryl is phenyl or naphthyl, are chosen for spectral investigations. The fullerene- $\mu$-oxo-dimer complexes have isolated packing of fullerenes in which fullerene molecule is embraced in a pocket built by porphyrins. Molecular configurations of the chromophore molecules and complexes are presented and discussed. The configuration and spectral properties of porphyrin-derived chromophore-fullerene adducts are also given.

The Fe $\mu$-oxo-dimer porphyrin was obtained by the typical method. After dissolving $0.5 \mathrm{~g} \mathrm{TPPFeCl} 3$ in $60 \mathrm{ml} \mathrm{CHCl}_{3}$ (1 hour reflux), $50 \mathrm{ml} 25 \% \mathrm{KOH}$ solution was added. The subsequent separation was used in order to purify the 
organic compound layer (in $\mathrm{CHCl}_{3}$ ) by chromatography (twice) on alumina column and eluted with chloroform. The first layer migrated is the FeTPPCl compound. The second corresponds to the (TPP-Fe $)_{2}-\mathrm{O}$ compound. The collected amount of $(\mathrm{TPP}-\mathrm{Fe})_{2}-\mathrm{O}$, as the main product, is concentrated through distillation. A dark-brown precipitate was obtained. This method is followed for (TPP-Fe $)_{2}-\mathrm{O}$, $(\mathrm{TNP}-\mathrm{Fe})_{2}-\mathrm{O}$ and $(\mathrm{TTP}-\mathrm{Fe})_{2}-\mathrm{O}$. The same synthesis method is suitable for the $\mathrm{Mn}$ compounds; the manganese $\mu$-oxo-dimer porphyrins was not reported in literature until now. The product consists in a green-brown powder.

The crystals of $(\mathrm{TXP}-\mathrm{Fe})_{2} \cdot \mathrm{C}_{60}$ complex were obtained by slow evaporation of toluene solution containing $20 \mathrm{mg}$ of $\mathrm{C}_{60}$ and $38 \mathrm{mg}$ of (TPP-Fe) ${ }_{2}-\mathrm{O}$ (1:1 molar ratio) under argon during a week (yield 90\%). The composition of (TXP-Fe $)_{2} \cdot \mathrm{C}_{60}$ was determined from the X-ray diffraction on a single crystal. Similar recipe has been used for $(\mathrm{TXP}-\mathrm{Fe})_{2} \cdot \mathrm{C}_{70}$ complexes.

The electronic and vibrational spectra of some $\mu$-oxo-dimer complexes of trivalent metals (Mn, Fe) with two different ligands: TPP and TNP, and fullerene $\left(\mathrm{C}_{60}\right.$ and $\left.\mathrm{C}_{70}\right)$ complexes with $\mu$-oxobis[5,10,15,20-tetraarylporphyrinatometal (III)] (MTXP $)_{2} \mathrm{O}$ dimer, where $\mathrm{M}=\mathrm{Fe}, \mathrm{Mn}$ and $\mathrm{X}=$ phenyl or naphthyl, were investigated at room temperature, in the $\mathrm{KBr}$ pellets containing dispersed compounds. The spectra were recorded in the range between 200 and $3500 \mathrm{~nm}$ with Perkin Elmer UV-Vis-NIR Lambda 19 spectrometer and in the range 400$7500 \mathrm{~cm}^{-1}$ with FT-IR Bruker Equinox 55 spectrometer. The room temperature Raman spectra of the crystals were collected with a Horiba Jobin Yvon LabRam HR800 spectrometer and appropriate microscope with excitation beam $\left(\lambda_{\text {ex }}=633 \mathrm{~nm}\right)$ from the He-Ne laser and $\lambda_{\text {ex }}=488 \mathrm{~nm}$ from the Ar laser. The power of the beam at the sample was less than $1 \mathrm{~mW}$ to avoid damages of the sample.

The initial optimization of the molecular geometry and normal vibrational modes calculation for $\mathrm{MnTNP}^{+}$cation was performed using ab initio Hartree-Fock method with standard basis set STO-3G (Gaussian 03W [10] package); electron excitations were calculated with the Hartree-Fock time-dependent self-consistent field method (TD-SCF) with the same standard basis set. Because the investigated molecules are very big, the calculations are extremely difficult and time consuming; moreover, the iron atom in some of the measured materials additionally complicates the calculations. It is necessary to mention that our attempts to use the density functional theory (DFT) and semi-empirical methods like Austin Model 1 (AM1) or parameterized model number 3 (PM3) were unsuccessful. Some mode description was made by visual inspection of the individual modes using the GaussView program. The normal modes assignment was performed based on the experimental and theoretical data.

\section{Results and discussion}

Electronic absorption spectra of the fullerene $\left(\mathrm{C}_{60}\right.$ or $\left.\mathrm{C}_{70}\right)$ complexes of $\mu$-oxo-dimer of Fe with tetraphenylporphyrin $\left((\mathrm{TPP}-\mathrm{Fe})_{2} \mathrm{O}-\mathrm{C}_{60 / 70}\right), \mu$-oxo-dimer 
(TPP-Fe $)_{2}-\mathrm{O}$ and fullerenes $\mathrm{C}_{60}$ and $\mathrm{C}_{70}$ are shown in Fig. 2. The spectrum of (TPP-Fe $)_{2}-\mathrm{O}$ is dominated by broad, complex band centered at $432 \mathrm{~nm}$ and several weaker bands observed at about 546, 320, 285, and $242 \mathrm{~nm}$. The former band should be assigned to $B$ band also called Soret band. This band is typical of porphyrin dyes and corresponds to a strong transition from the ground state of the second excited state $S_{0} \rightarrow S_{2}$; it appears usually between 380 and $460 \mathrm{~nm}$. For the same central metal, their position depends on the porphyrinic ligand, and of the substituents placed in meso-position of the macrocycle (phenyl, naphtyl, tolyl) [11]. The Soret band shows doublet structure in porphyrin dimers [12]. The band adequate to the Soret one predominates over remaining absorption bands of (TPP-Fe $)_{2} \mathrm{O}-\mathrm{C}_{60}$ and (TPP-Fe $)_{2} \mathrm{O}-\mathrm{C}_{70}$ complexes; the bands of the fullerenes are scarcely detectable. The main spectral change after the fullerene complexes formation is a decrease in the short-wave component of the broad band. The spectra of the fullerenes $\mathrm{C}_{60}$ and $\mathrm{C}_{70}$, shown also in both Figs. 2 and 3 , are dominated by the bands at 264, 340, and about $450 \mathrm{~nm}$ for the former and at $245,281,391,523$, and $577 \mathrm{~nm}$ for the later, respectively. Similar bands have been observed and assigned to appropriate dipole-allowed electronic transitions by Leach et al. [13].

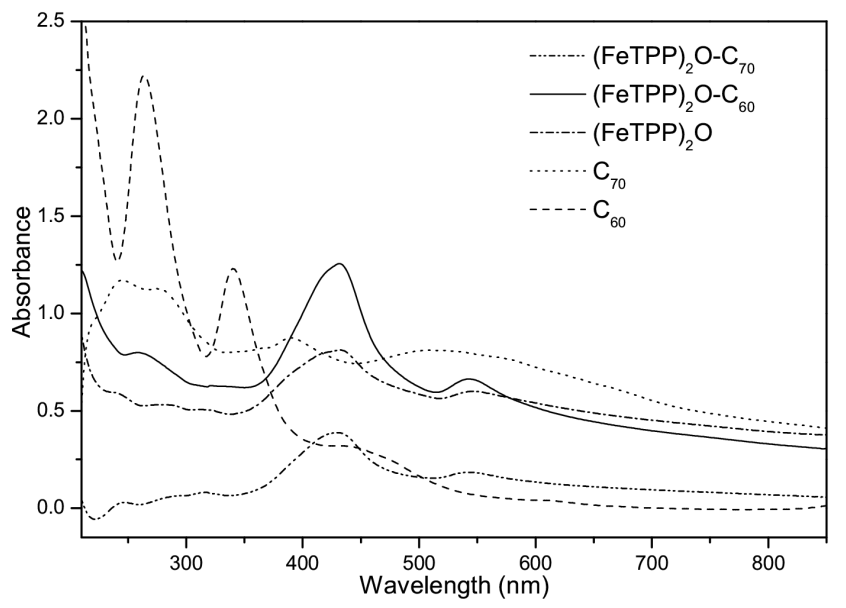

Fig. 2. Electronic absorption spectra of fullerene $\left(\mathrm{C}_{60}\right.$ and $\left.\mathrm{C}_{70}\right)$ complexes of $\mu$-oxo-dimer of Fe with tetraphenylporphyrin (TPP-Fe) ${ }_{2} \mathrm{O}-\mathrm{C}_{60} / 70, \mu$-oxo-dimer (TPP-Fe) ${ }_{2}-\mathrm{O}$ and fullerenes $\mathrm{C}_{60}$ and $\mathrm{C}_{70}$.

Experimental electron absorption spectra of fullerene $\mathrm{C}_{60}$ and $\mathrm{C}_{70}$ complexes of $\mu$-oxo-dimer of $\mathrm{Mn}$ with tetranaphthylporphyrin (TNP-Mn) ${ }_{2} \mathrm{O}-\mathrm{C}_{60 / 70}, \mu$-oxo-dimer (TNP-Mn) ${ }_{2}-\mathrm{O}$ and fullerenes $\mathrm{C}_{60}$ and $\mathrm{C}_{70}$ are shown in Fig. 3. The spectrum of (TNP-Mn) ${ }_{2} \mathrm{O}_{-} \mathrm{C}_{60}$ contains the bands at 261, 337, 379, 419, 487, 591, and $631 \mathrm{~nm}$; only the bands at 261,337, and $487 \mathrm{~nm}$ are relatively strong and well separated. The bands at 261 and $337 \mathrm{~nm}$ correspond to $\mathrm{C}_{60}$ dipole-allowed elec- 


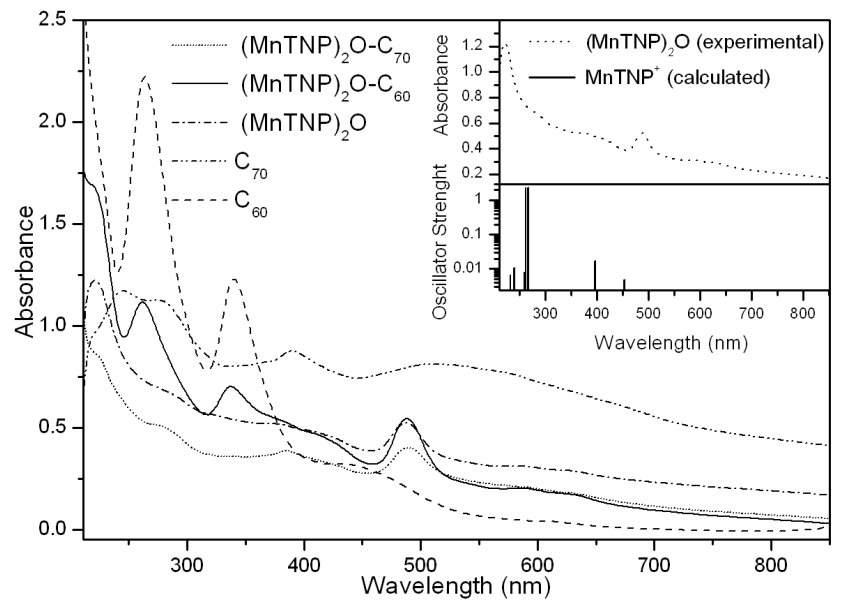

Fig. 3. Electronic absorption spectra of fullerene $\mathrm{C}_{60}$ and $\mathrm{C}_{70}$ complexes of $\mu$-oxo-dimer of $\mathrm{Mn}$ with tetranaphthylporphyrin (TNP-Mn) $)_{2} \mathrm{O}-\mathrm{C}_{60 / 70}, \mu$-oxo-dimer (TNP-Mn $)_{2}-\mathrm{O}$ and fullerenes $\mathrm{C}_{60}$ and $\mathrm{C}_{70}$. In the inset experimental spectrum of (TNP-Mn $)_{2}-\mathrm{O}$ and calculated excitations of cation are shown.

tronic transitions usually observed at 264 and $340 \mathrm{~nm}$, respectively, but the band at $487 \mathrm{~nm}$ is assigned to $\mu$-oxo-dimer's band at $488 \mathrm{~nm}$. Hypsochromic shifts of the fullerene bands by $3 \mathrm{~nm}$ and small bathochromic shift of the $\mu$-oxo-dimer band testify to charge transfer after the complex formation. Similar effect can be observed for (TNP-Mn) $)_{2} \mathrm{O}-\mathrm{C}_{70}$ complex. The bands assigned to $\mathrm{C}_{70}$ are registered at 283 and $385 \mathrm{~nm}$ and to the $\mu$-oxo-dimer - at $489 \mathrm{~nm}$. Some bands in many fullerene complexes and adducts are strongly blue-shifted and broadened as well, e.g. in the bis-linked TTF-fullerene derivatives [14, 15], perylenediimide-fullerene dyad [16], fullerene-modified porphyrin dyad [11], and meso,meso-linked oligoporphyrin bearing one or two fullerene moieties [17].

In order to interpret observed electronic bands of (TNP-Mn) $)_{2}-\mathrm{O}$, quantum chemical calculations of excited states of $\mathrm{MnTNP}^{+}$cation were performed with TD-SCF using the standard basis set STO-3G. In the inset of Fig. 3, the experimental spectrum of (TNP-Mn) ${ }_{2}-\mathrm{O}$ and calculated excitations of $\mathrm{MnTNP}^{+}$ cation are shown. The simulated excitations assigned to the Soret band are located between 400 and $450 \mathrm{~nm}$. The correspondence of experimental and calculated excitations is acceptable for such complicated molecule as $\mu$-oxo-dimer $(\mathrm{TNP}-\mathrm{Mn})_{2}-\mathrm{O}$ is.

Infrared absorption spectra of the fullerene complexes with various $\mu$-oxo-dimers were recorded in the large spectral range, but only for the range from 400 to $1500 \mathrm{~cm}^{-1}$, are presented in Fig. 4. In this range, the most interesting vibrational features occur. The typical IR spectra evolution is shown for (TNP-Mn) ${ }_{2} \mathrm{O}-\mathrm{C}_{60}$ and (TNP-Mn) ${ }_{2} \mathrm{O}-\mathrm{C}_{70}$ complexes; as references, the spectra of $\mu$-oxo-dimer (TNP-Mn) $)_{2}-\mathrm{O}$ and fullerenes $\mathrm{C}_{60}$ and $\mathrm{C}_{70}$ are also shown. The spec- 
tra of both complexes are dominated by vibrational bands of the $\mu$-oxo-dimer. The distinct band $1460 \mathrm{~cm}^{-1}$ is assigned to $\mathrm{C}=\mathrm{C}$ vibrations, the band $1250 \mathrm{~cm}^{-1}$ with weak, supplementary bands between 1170 and $1350 \mathrm{~cm}^{-1}$ are attributed to $\mathrm{C}-\mathrm{H}$ in-plane bending vibrations, the same attribution is suggested for broad and complex bands in the range 1000 to $1150 \mathrm{~cm}^{-1}$. In fact, an unusual shape of the band is rather strange but the $\mu$-oxo-dimer containing two tetranaphtylporphyrinatomanganese rings chemically bonded by metal-oxygen-metal bond is a very big and complex molecule, which displays several $\mathrm{C}-\mathrm{H}$ in- and out-of-plane vibrations of various molecular fragments of Mn-porphyrin, phenyl and naphthyl groups. All these vibrations overlap in the range under discussion. Similar effect has been observed by us for much smaller meso,meso-linked oligoporphyrin bearing one or two fullerene moieties [17]. The strong and broad bands below $900 \mathrm{~cm}^{-1}$ are probably dominated by overlapping of out of plane $\mathrm{C}-\mathrm{H}$ deformations of the cycles.

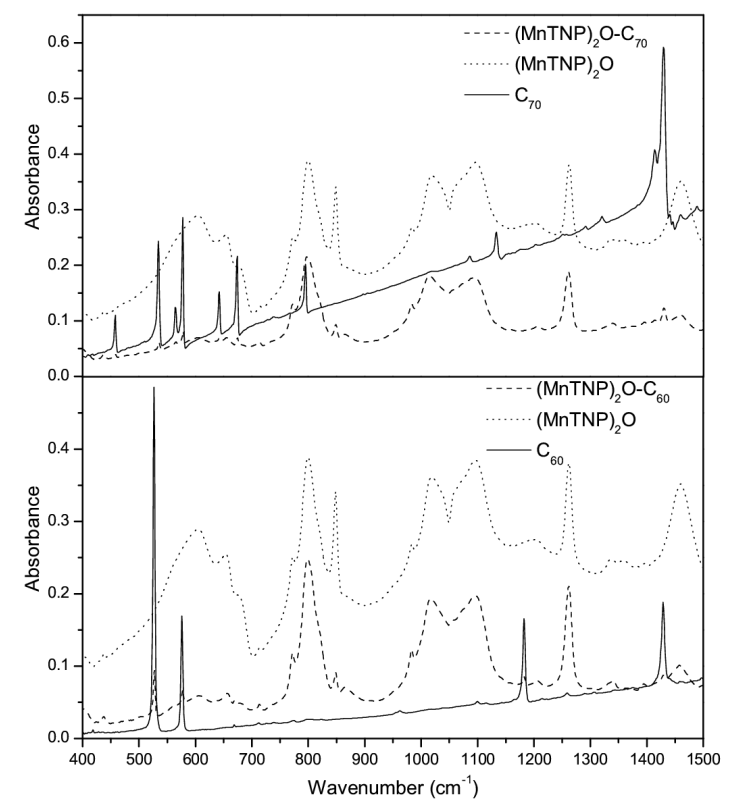

Fig. 4. Vibrational absorption spectra of fullerene $\mathrm{C}_{60}$ and $\mathrm{C}_{70}$ complexes of $\mu$-oxo-dimer of Mn with TNP; pristine $\mu$-oxo-dimer and respective fullerenes are added for comparison.

All above mentioned vibrations are observed in very similar form and at nearly the same frequencies in the complexes with the fullerenes. Of course, the lines typical of $\mathrm{C}_{60}$ or $\mathrm{C}_{70}$ fullerenes are detectable at the same frequencies as for pristine fullerenes. Thus, the vibrational spectrum of the complexes is a superposition of the spectral characteristics of both fullerene and $\mu$-oxo-dimer. The small, nearly undetectable shifts of band frequencies suggest that charge transfer between the species forming the investigated complexes is very small. Thus, 
Description of the calculated Raman lines of the $\mathrm{MnTNP}^{+}$cation.

\begin{tabular}{|c|c|c|}
\hline $\begin{array}{l}\text { Indication } \\
\text { of the line }\end{array}$ & $\begin{array}{c}\text { Raman } \\
\text { shift } \\
{\left[\mathrm{cm}^{-1}\right]}\end{array}$ & Approximate description \\
\hline 1 & 255 & out of plane deformation \\
\hline $2 \mathrm{a}$ & 357 & in plane $\mathrm{Mn}-\mathrm{N}$ stretching and naphthalene groups deformation \\
\hline 2 & 406 & in plane $\mathrm{Mn}-\mathrm{N}$ stretching and $\mathrm{C}=\mathrm{C}$ stretching \\
\hline $2 \mathrm{~b}$ & 449 & out of plane deformation \\
\hline 3 & 560 & in plane $\mathrm{N}-\mathrm{Mn}-\mathrm{N}$ bending and naphthalene groups deformation \\
\hline 4 & 650 & out of plane deformation and naphthalene groups deformation \\
\hline 5 & $\begin{array}{l}736 \\
755 \\
758\end{array}$ & mainly naphthalene groups deformation \\
\hline 6 & $\begin{array}{l}839 \\
842 \\
851\end{array}$ & $\begin{array}{l}\text { out of plane } \mathrm{C}-\mathrm{H} \text { bending (all } \mathrm{C}-\mathrm{H} \text { bonds) and out of plane } \\
\text { deformation }\end{array}$ \\
\hline 7 & $\begin{array}{l}887 \\
936 \\
968\end{array}$ & $\begin{array}{l}\text { out of plane } \mathrm{C}-\mathrm{H} \text { bending }(\mathrm{C}-\mathrm{H} \text { bonds in naphthalene groups } \\
\text { only) }\end{array}$ \\
\hline 8 & 1000 & $\begin{array}{l}\text { in plane } \mathrm{C}-\mathrm{C}=\mathrm{C} \text { bending (center) and } \mathrm{C}-\mathrm{H} \text { bending (naphtha- } \\
\text { lene groups) }\end{array}$ \\
\hline 9 & 1033 & $\begin{array}{l}\text { in plane } \mathrm{C}-\mathrm{H} \text { bending (center) and out of plane } \mathrm{C}-\mathrm{H} \text { bending } \\
\text { (naphthalene groups) }\end{array}$ \\
\hline 10 & 1151 & $\begin{array}{l}\text { in plane } \mathrm{Mn}-\mathrm{N} \text { stretching (symmetrical) and out of plane } \mathrm{C}-\mathrm{H} \\
\text { bending }\end{array}$ \\
\hline 11 & $\begin{array}{l}1239 \\
1240\end{array}$ & in plane $\mathrm{C}-\mathrm{H}$ bending (center only) \\
\hline 12 & 1332 & in plane $\mathrm{Mn}-\mathrm{N}$ stretching and in plane $\mathrm{C}-\mathrm{H}$ bending (center) \\
\hline
\end{tabular}

the complexes of fullerenes with selected $\mu$-oxo-dimers are of van der Waals type. Contrary to these and similar molecular complexes, the formation of chemically bonded fullerene-porphyrin dyad usually causes important changes in the electron distribution on the porphyrin moiety. This effect dramatically affects the vibrational force constants, and as a result, the frequencies and line widths of the porphyrin moiety bands [17].

Raman scattering spectra, because of different selection rules, give complementary information on normal vibrations observed in the IR. This is why we have recorded the Raman spectra of the fullerene $\mathrm{C}_{60}$ and $\mathrm{C}_{70}$ complexes of $\mu$-oxo-dimer of Mn with TNP and adequate $\mu$-oxo-dimer, excited with $\lambda_{\text {ex }}=488 \mathrm{~nm}$ (Fig. 5 ). The spectra are dominated by the Raman lines of the $\mu$-oxo-dimer though the 


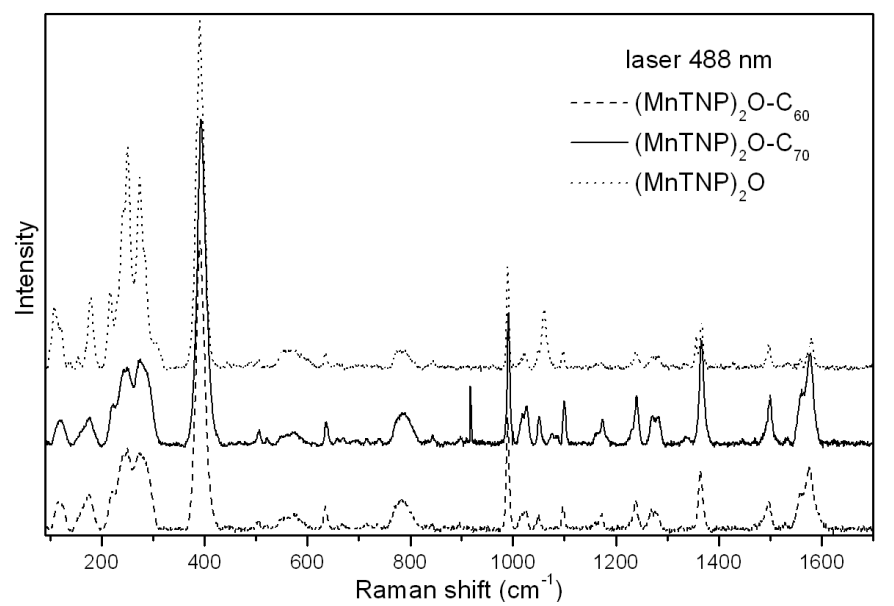

Fig. 5. Raman scattering spectra of fullerene $\mathrm{C}_{60}$ and $\mathrm{C}_{70}$ complexes of $\mu$-oxo-dimer of Mn with TNP together with the respective $\mu$-oxo-dimer, excited with $\lambda_{\text {ex }}=488 \mathrm{~nm}$.

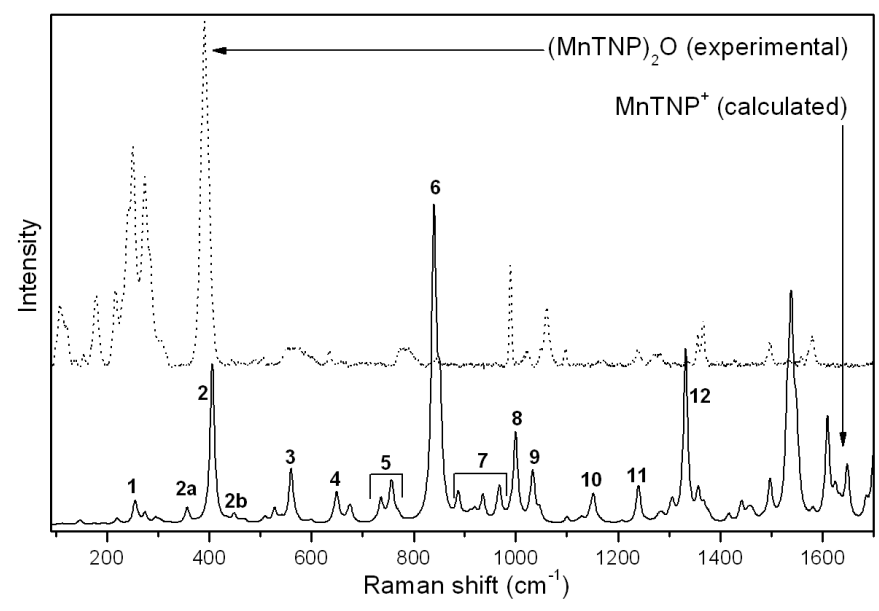

Fig. 6. Experimental Raman spectrum of (MnTNP $)_{2} \mathrm{O}$ and calculated spectrum of the respective cation (see Table for the calculated Raman lines description).

weak lines of the fullerenes are detectable. Analysis of the spectra of two fullerene complexes confirms our conclusions from the infrared studies that they are superposition of the spectra of both moieties of the complex. The intensities of the Raman lines strongly depend on the wavelength of the exciting light. Detailed analysis of the spectra of fullerene $\mathrm{C}_{70}$ complex of $\mu$-oxo-dimer of $\mathrm{Mn}$ for $\lambda_{\text {ex }}=488 \mathrm{~nm}$ and $633 \mathrm{~nm}$ confirms above conclusion.

Experimental Raman spectrum of (MnTNP $)_{2} \mathrm{O}$ and calculated spectrum of adequate cation are shown in Fig. 6. An assignment of the main vibrational bands of the cation was made taking into consideration the experimental data 
and results of the normal mode analysis. Description of the Raman lines of the cation is collected in Table. These data enable us to assign the observed bands of $\mu$-oxo-dimer of Mn as well as other investigated spectra.

\section{Conclusion}

It was stated that charge redistribution occurs in both fullerene and porphyrin moieties upon formation of the fullerene- $\mu$-oxo-dimer complexes. This effect is mainly observed as detectable shifts and/or small broadening of both electronic and vibrational bands in comparison with respective free $\mu$-oxo-dimers and fullerenes features. More detailed spectral studies go on.

\section{Acknowledgments}

We gratefully acknowledge Dr. I. Olejniczak (Poznań) for critical reading of the manuscript.

\section{References}

[1] F. Diederich, M. Gómez-López, Chem. Soc. Rev. 28, 263 (1999).

[2] H.W. Kroto, J.R. Heath, S.C. O'Brien, R.F. Curl, R.E. Smalley, Nature 318, 162 (1985).

[3] M.S. Dresselhaus, G. Dresselhaus, P.C. Eklund, Science of Fullerenes and Carbon Nanotubes, Academic Press, San Diego 1996.

[4] Fullerenes and Related Structures, Ed. A. Hirsch, Springer, Berlin 1999.

[5] P.A. Liddell, J.P. Sumida, A.N. Macpherson, L. Noss, G.R. Seely, K.N. Clark, A.L. Moore, D. Gust, Photochem. Photobiol. 60, 537 (1994).

[6] D. Holten, D.F. Bocian, J.S. Lindsey, Acc. Chem., Res. 35, 57 (2002).

[7] M. Prato, J. Mat. Chem. 7, 1097 (1997).

[8] H. Imahori, K. Tamaki, Y. Araki, Y. Sekiguchi, O. Ito, Y. Sakata, S. Fukuzumi, J. Am. Chem. Soc. 124, 5165 (2002).

[9] R.P. Socoteanu, R.M. Ion, D. Licsandru, A. Ureche-Fotea, Progress in Catalysis 9, 57 (2000).

[10] Gaussian 03, Revision B.05, M.J. Frisch, G.W. Trucks, H.B. Schlegel, G.E. Scuseria, M.A. Robb, J.R. Cheeseman, J.A. Montgomery, Jr., T. Vreven, K.N. Kudin, J.C. Burant, J.M. Millam, S.S. Iyengar, J. Tomasi, V. Barone, B. Mennucci, M. Cossi, G. Scalmani, N. Rega, G.A. Petersson, H. Nakatsuji, M. Hada, M. Ehara, K. Toyota, R. Fukuda, J. Hasegawa, M. Ishida, T. Nakajima, Y. Honda, O. Kitao, H. Nakai, M. Klene, X. Li, J.E. Knox, H.P. Hratchian, J.B. Cross, C. Adamo, J. Jaramillo, R. Gomperts, R.E. Stratmann, O. Yazyev, A.J. Austin, R. Cammi, C. Pomelli, J.W. Ochterski, P.Y. Ayala, K. Morokuma, G.A. Voth, P. Salvador, J.J. Dannenberg, V.G. Zakrzewski, S. Dapprich, A.D. Daniels, M.C. Strain, O. Farkas, D.K. Malick, A.D. Rabuck, K. Raghavachari, J.B. Foresman, J.V. Ortiz, Q. Cui, A.G. Baboul, S. Clifford, J. Cioslowski, B.B. Stefanov, G. Liu, A. Liashenko, P. Piskorz, I. Komaromi, R.L. Martin, D.J. Fox, T. Keith, M.A. Al-Laham, C.Y. Peng, A. Nanayakkara, M. Challacombe, P.M.W. Gill, B. Johnson, W. Chen, M.W. Wong, C. Gonzalez, J.A. Pople, Gaussian, Inc., Pittsburgh PA, 2003. 
[11] M. Gouterman, in: The Porphyrins, Vol. III, Ed. D. Dolphin, Academic Press, New York 1978, p. 1.

[12] A. Łapiński, A. Graja, I. Olejniczak, A. Bogucki, M. Połomska, J. Baffreau, L. Perrin, S. Leroy-Lhez, P. Hudhomme, Mol. Cryst. Liq. Cryst. 447, 87 (2006).

[13] S. Leach, M. Vervloet, A. Desprès, E. Bréheret, J.P. Hare, T.J. Dennis, H.W. Kroto, R. Taylor, D.R.M. Walton, Chem. Phys. 160, 451 (1992).

[14] I. Olejniczak, A. Bogucki, M. Golub, A. Graja, D. Kreher, M. Cariou, A. Gorgues, P. Hudhomme, Full., Nanotubes Carb. Nanostructures 10, 117 (2002).

[15] B. Laskowska, A. Łapiński, A. Graja, P. Hudhomme, Chem. Phys. 332, 289 (2007).

[16] A. Łapiński, A. Graja, I. Olejniczak, A. Bogucki, H. Imahori, Chem. Phys. 305, 277 (2004).

[17] A. Graja, I. Olejniczak, A. Bogucki, D. Bonifazi, F. Diederich, Chem. Phys. 300, 227 (2004). 